\title{
Correction to: Joint Preservation of the Knee
}

\author{
Adam B. Yanke and Brian J. Cole
}

Correction to: A. B. Yanke, B. J. Cole (eds.), Joint Preservation of the Knee, https://doi.org/10.1007/978-3-030-01491-9

Dr. Trevor R. Gulbrandsen's affiliation in the book has been updated and a typo in the city has been corrected from Lowa to Iowa.

The correct version of affiliation is below:

Department of Orthopaedic Surgery, University of Iowa Hospitals and Clinics, Iowa City, IA, USA.

The updated online versions of these chapters can be found at https://doi.org/10.1007/978-3-030-01491-9_10

https://doi.org/10.1007/978-3-030-01491-9_14 